\title{
Numerical analysis of stiffened plates subjected to transverse uniform load through the constructal
} design method

\author{
Vinícius Torres Pinto ${ }^{a}$, Luiz Alberto Oliveira Rocha ${ }^{b}$, Elizaldo Domingues dos Santos ${ }^{a}$ and \\ Liércio André Isoldi ${ }^{a^{*}}$
}

${ }^{a}$ Ocean Engineering Graduate Program (PPGEO), Federal University of Rio Grande - FURG, Rio Grande. RS, Brazil ${ }^{b}$ Mechanical Engineering Graduate Program, University of Vale do Rio dos Sinos - UNISINOS, São Leopoldo, RS, Brazil

\begin{tabular}{l}
\hline A R T I C L E I N F O \\
\hline Article history: \\
Received 1 February 2021 \\
Accepted 17 September 2021 \\
Available online \\
17 September 2021 \\
\hline Keywords: \\
Plates with Stiffeners \\
Numerical Simulation \\
Constructal Design \\
Deflection \\
Rectangular Stiffeners \\
Trapezoidal Stiffeners
\end{tabular}
\begin{abstract}
A B S T R A C T
When it comes to engineering, high performance is always a desired goal. In this context, regarding stiffened plates, the search for better geometric configurations able to minimize the out-of-plane displacements become interesting. So, this study aimed to analyze several stiffened plates defined by the Constructal Design Method (CDM) and solved through the Finite Element Method (FEM) using the ANSYS ${ }^{\circledR}$ software. After that, these plates are compared among each other through the Exhaustive Search (ES) technique. To do so, a non-stiffened rectangular plate was adopted as reference. Then, a portion of its steel volume was converted into stiffeners through the $\phi$ parameter, which represents the ratio between the volume of the stiffeners and the total volume of the reference plate. Taking into consideration the value of $\phi=0.3,75$ different stiffened plates arrangements were proposed: 25 with rectangular stiffeners oriented at $0^{\circ} ; 25$ with rectangular stiffeners oriented at $45^{\circ}$ and 25 with trapezoidal stiffeners oriented at $0^{\circ}$. Maintaining the total volume of material constant, it was investigated the geometry influence on the maximum deflection of these stiffened plates. The results have shown trapezoidal stiffeners oriented at $0^{\circ}$ are more effective to reduce the maximum deflections than rectangular stiffeners also oriented at $0^{\circ}$. It was also observed that rectangular stiffeners oriented at $45^{\circ}$ presented the smallest maximum deflections for the majority of the analyzed cases, when compared to the trapezoidal and rectangular stiffeners oriented at $0^{\circ}$.
\end{abstract}

\section{Introduction}

Steel plates are structural components employed in a broad number of engineering structures and are mainly characterized by having its thickness considerably smaller than the length and width. Generally, the loads applied to the plates are perpendicular to the plane and are transmitted in two directions, creating shear, bending and torsion forces to resist the loadings. Therefore, plates present a good combination of lightness and stiffness (Ugural 2010; Ventsel \& Krauthammer 2001). Seeking to improve the flexural rigidity, once the slenderness is a plate feature, it is a common practice to weld stiffeners on its plane, normally in transverse and longitudinal directions. The versatility of the plates enables them to be used in different structures, such as oil rigs, ship hulls (see Fig. 1) and bridge decks (Bedair, 2009). One of the greatest challenges in the analysis of stiffened plates is the difficulty of finding analytical equations to precisely describe its mechanical behavior. When it comes to non-stiffened plates, stress and displacement can be found by employing the classic Kirchhoff differential equation, through the solutions proposed by Navier or Levy (Szilard, 2004). Meantime, regarding stiffened plates, among the rare analytical solutions existing, it is possible to quote Pama and Cusens (1967), as well, Powell and Ogden (1969), that proposed to idealize the stiffened plate into an equivalent orthotropic plate. However, according to Szilard (2004), analytical

* Corresponding author.

E-mail addresses: liercioisoldi@furg.br (L.A. Isoldi) 
stiffened plate solutions have some limitations, such as, relatively small uniform stiffeners and closely spaced. For this reason, numerical methods become an interesting alternative to solve such problems.

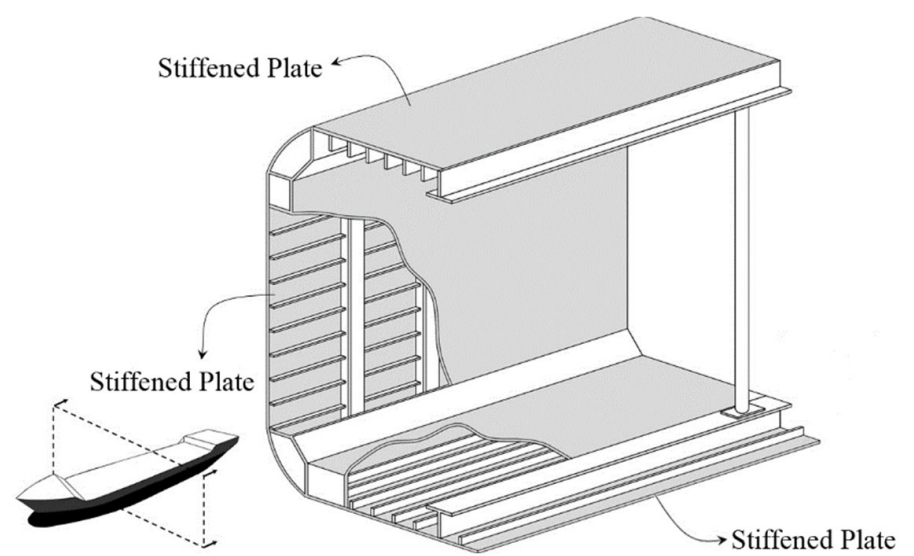

Fig. 1. Cross section of a ship.

Several works adopting the numerical approach to investigate the mechanical behavior of stiffened plates can be found in the literature. Mukhopadhyay and Satsangi (1984), through the Finite Element Method (FEM), presented a formulation to solve stiffened plates based on isoparametric finite elements, which allowed considering transverse shear deformations and redefining the stiffeners positioning without modifying the finite element mesh. O'Leary and Harari (1985) developed a study to analyze stiffened plates using the FEM from a constraint variational principle, where the restrictions between the plate and the stiffener were imposed through Lagrange multipliers. In its turn, Tanaka et al. (2000) employed the Boundary Element Method (BEM) in order to analyze stiffened plates, where the forces and moments between the plate and the stiffener were considered as unknowns and estimated through interpolation functions in the numerical solution. Sapountzakis and Katsikadelis (2000) using the Analog Equation Method (AEM) proposed an approach to analyze stiffened plates, where the plate and stiffeners were treated separately and the forces that produce transverse deflection and deformation in the plate and stiffeners were determined by using continuity conditions. In addition, since the advent of high-performance computing, the use of commercial software on the analysis of structures has become a popular practice. Using ANSYS ${ }^{\circledR}$, Singh et al. (2015) performed a parametric analysis on stiffened plates under bending considering different loads and boundary conditions. Troina et al. (2020) applied the Constructal Design Method (CDM) associated with computational models developed on ANSYS ${ }^{\circledR}$ software, to found through the Exhaustive Search (ES) technique the optimized stiffened plates capable to minimize the central deflection on stiffened plates. As well as, Nogueira et al. (2021) used the same methodology applied by Troina et al. (2020), but in its turn, focused on minimize the maximum and the central out-of-plane deflections on stiffened plates, varying the heights of transverse and longitudinal stiffeners. Therefore, the present study aims to analyze the mechanical behavior of stiffened plates under bending defined by the CDM solved through computational models developed in ANSYS ${ }^{\circledR}$ software, which is based on FEM. Employing the Exhaustive Search (ES) technique, three different situations of stiffened plates arrangements were investigated: i) rectangular stiffeners oriented at $0^{\circ}$; ii) rectangular stiffeners oriented at $45^{\circ}$; and iii) trapezoidal stiffeners oriented at $0^{\circ}$. For each of these three situations, the number of stiffeners was varied and the results compared to each other. However, it is important to highlight the differences among this study and the aforementioned studies of Troina et al. (2020) and Nogueira et al. (2021). Here it was investigated the influence of the rectangular stiffeners at $45^{\circ}$ and the trapezoidal stiffeners at $0^{\circ}$; while in both previous works only rectangular stiffeners at $0^{\circ}$ were considered.

\section{Computational modeling}

Currently when it comes to structural engineering problems, computational modeling is a fundamental tool, which allows analyzing and reanalyzing hypotheses till extreme values with safety and accuracy. The numerical methods such as Finite Difference Method (FDM) and Finite Element Method (FEM), which are the basis of CAD tools (Computer-Aided Design), are employed on scientific and industrial solutions that deals with analysis, optimization and development of products and projects (Rappaz et al., 2010; Steinhauser, 2008). The computational modeling of the stiffened plates used in this study was performed on ANSYS ${ }^{\circledR}$ software, which is based on the FEM. Briefly, FEM consists in discretizing a complex continuum domain into elements of finite size interconnected through nodes, composing a mesh. Therefore, all elements are combined creating a system that represents the analyzed continuum model (Thompson \& Thompson 2017).

In the present work, all numerically simulated plates were discretized using the triangular version of the two-dimensional shell-type finite element SHELL281. This element is adequate to model thin plates, having 6 degrees of freedom on each node, being 3 translations on $x, y$ e $z$ directions and 3 rotations around these axes (Ansys, 2019). 


\subsection{Computational Model Verification}

The case used for the verification of the computational model (see Fig. 2) was anteriorly solved by Troina et al. (2018) with the three-dimensional element SOLID95 in the hexahedral version, also in ANSYS ${ }^{\circledR}$ software.

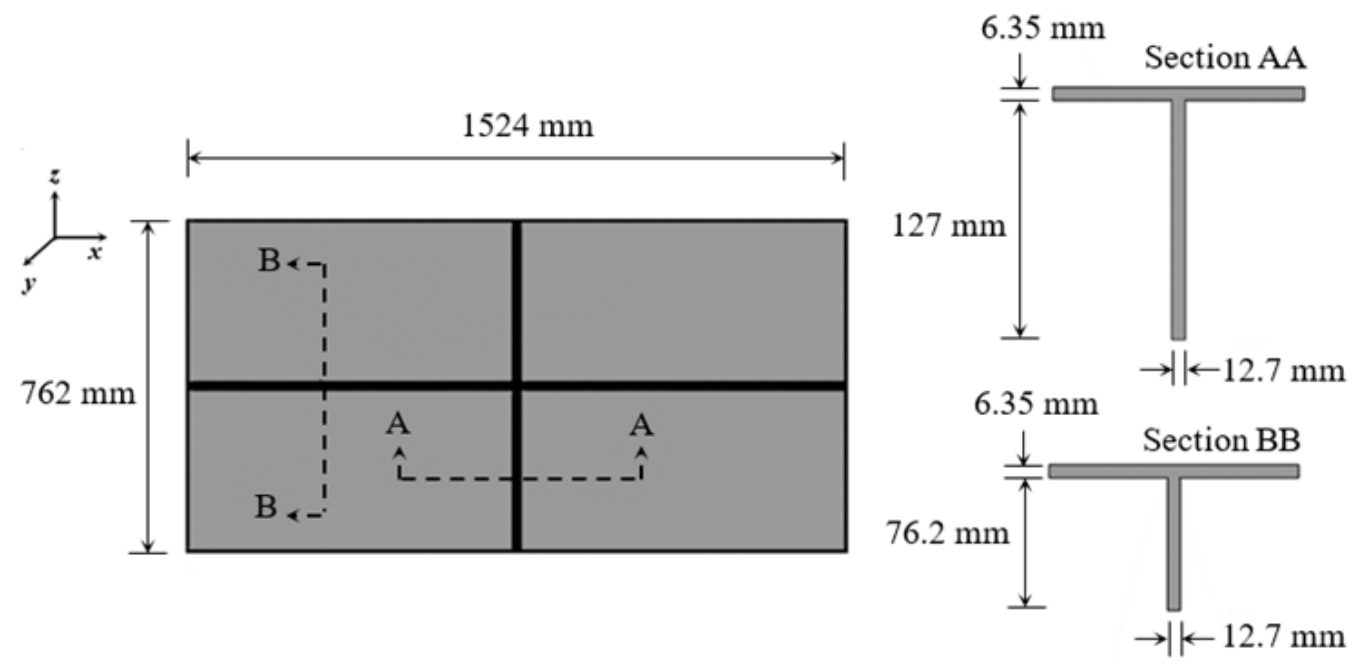

Fig. 2. Rectangular plate with 2 orthogonal stiffeners.

The plate of Fig. 2 was subjected to a uniform transverse loading of $68.95 \mathrm{kPa}$ with boundary conditions of simply supported edges, having a material with an elastic modulus of $206.8427 \mathrm{GPa}$ and Poisson's ratio of 0.3. The proposed case was numerically solved using the element SHELL281 in the triangular version with a mesh of 30,400 elements, defined from the mesh convergence test shown in Fig. 3, which also presents the result obtained by Troina et al. (2018). It is seen from Fig. 3 that the difference between the central deflections $\left(U_{z}\right)$ found in the present study and in Troina et al. (2018) is $1.08 \%$, verifying the proposed computational model.

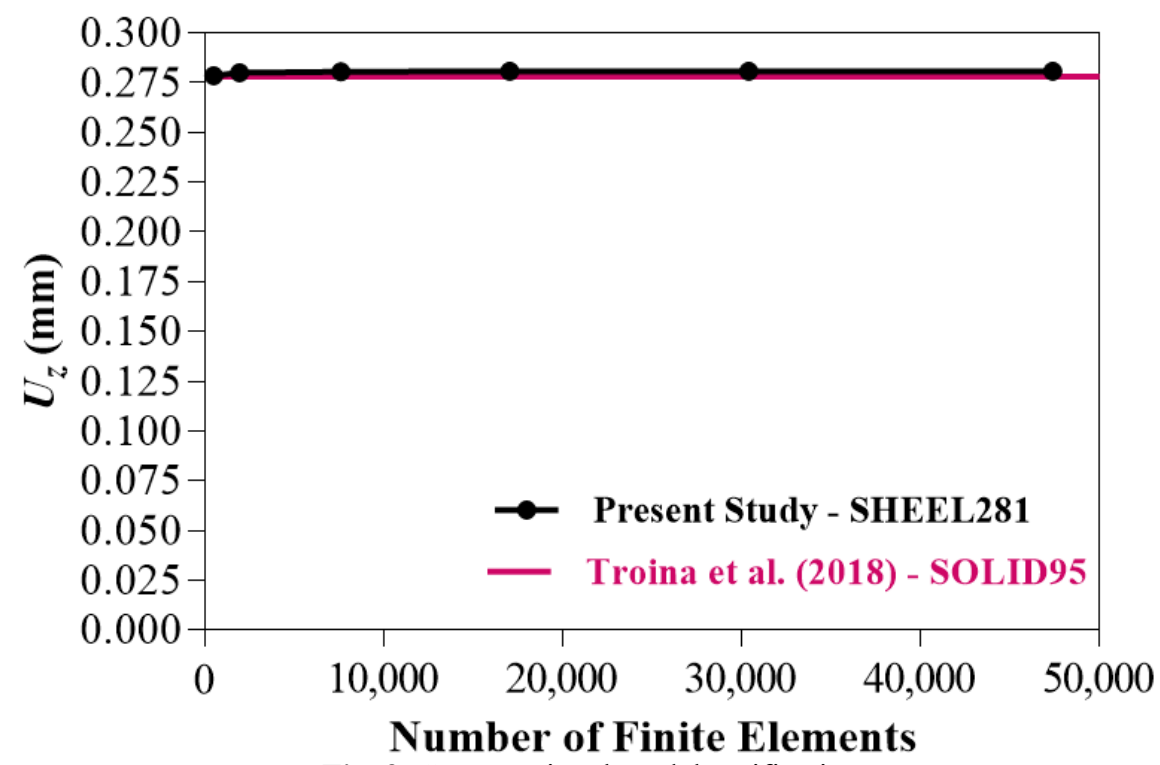

Fig. 3. Computational model verification

\subsection{Computational Model Validation}

The experimental test carried out by Carrijo et al. (1999) was used for the validation of the numerical model. The square plate presented in Fig. 4 was subjected to a uniform transverse loading of $0.96 \mathrm{kPa}$, and has as boundary conditions just its four corners simply supported. The material has an elastic modulus of $2.5 \mathrm{GPa}$, and a Poisson's ratio of 0.36 . 


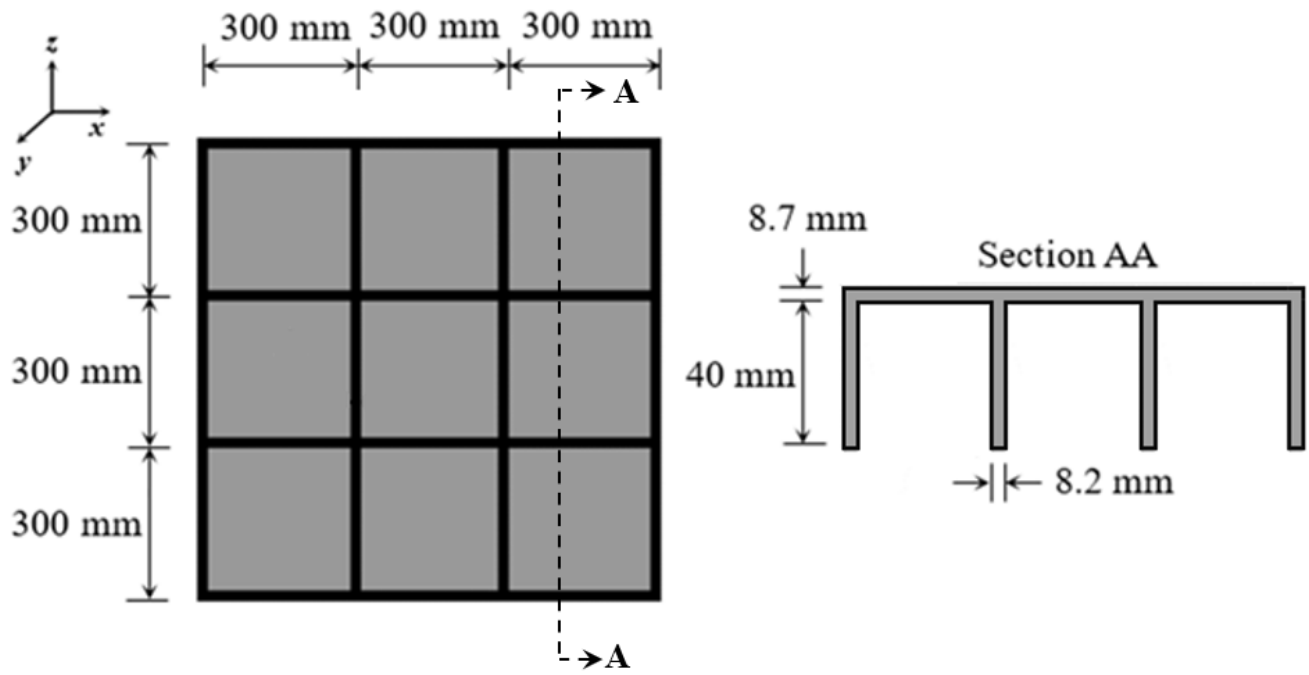

Fig. 4. Square plate with eight stiffeners.

Using the finite element SHELL281 the experiment was numerically solved. The mesh used to discretize the numerical model was defined through a mesh convergence test, totalizing 5,070 triangular elements, as shown in Fig. 5, which also presents the result obtained by Carrijo et al. (1999). From the Fig. 5 it is possible to notice an error of $4.58 \%$ for the central deflection of $U_{z}=6.505 \mathrm{~mm}$, comparing the present study and the experimental result (that showed a value of $6.220 \mathrm{~mm}$ ), validating the computational model.

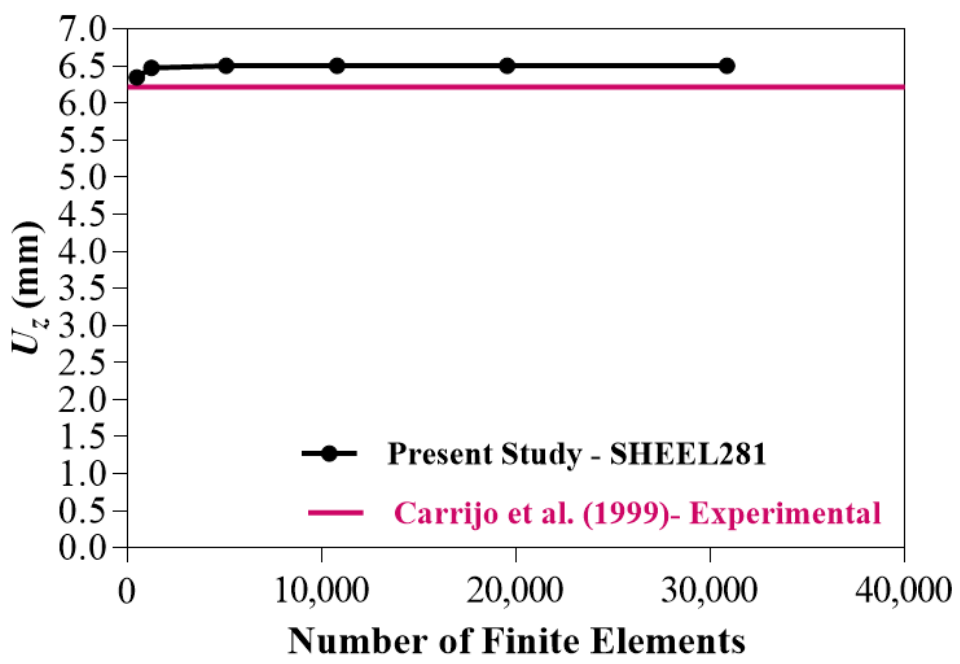

Fig. 5. Computational model validation.

\section{Constructal Design Method (CDM)}

The geometric forms that occur in nature are flow systems governed by a physical principle, the Constructal Law. This physical law states that "For a finite-size system to persist in time (to live), it must evolve in such a way that it provides easier access to the imposed (global) currents that flow through it" (Bejan \& Zane 2012). The CDM is the application of the Constructal Law in practical situations, based on restrictions and performance indicators. The performance of a system contains inherent restrictions, which may include the space allocated to the system, available material and components, allowable temperature, pressure or stress ranges. Once defined the restrictions and the performance indicators of a system, certain parameters and geometries are varied aiming to evaluate their influence on the performance indicator. In addition, if an optimization method is associated with the CDM, it is possible to identify the optimized configuration in such a way that the flow architecture achieves the best possible performance (Reis, 2006, Dos Santos et al., 2017). There are a large number of studies applying the CDM in heat transfer and fluid mechanics engineering problems. However, its application in structural engineering problems is viable in a similar way, as presented by Bejan and Lorente (2008), Lorente et al. (2010), and Isoldi et al. (2013) and recently scientifically proved by De Silveira et al. (2021). According to Bejan and Lorente (2008) the approach regarding structural problems is possible once in this kind of situation the flow is related to the flow of stresses. In this case, the optimal geometric configuration is one that presents a better distribution of the imperfections, i.e., a better distribution of the regions submitted to the allowable stress of the material. This is just possible when there is a better 
distribution of the flow of stresses throughout the entire structure. Aiming to improve the structural performance of plates, studies applying the CDM associate to Exhaustive Search (ES) technique have been published dealing with: buckling of perforated plates (Helbig et al. 2018; and Da Silva et al. 2019); buckling of stiffened steel plates (Lima et al., 2018 and 2020), and bending of stiffened steel plates (Cunha et al., 2018; De Queiroz et al., 2019; Amaral et al., 2019; Pinto et al., 2019; Troina et al., 2020; Nogueira et al., 2021).

In the present study, the application of the CDM consists in a geometrical analysis of stiffened plates under bending. For that, a non-stiffened plate with length $a=2000 \mathrm{~mm}$, width $b=1000 \mathrm{~mm}$ and thickness $t=20 \mathrm{~mm}$ was taken as reference. Then, maintaining the total volume of material constant, as well as, $a=2000 \mathrm{~mm}, b=1000 \mathrm{~mm}$, a steel portion of the reference plate was entirely removed from its thickness and transformed into stiffeners through $\phi$ parameter, which represents the ratio between the steel volume of stiffeners and the steel volume of the reference plate. A value of $\phi=0.3$ was adopted, i.e., $30 \%$ of the material from the reference plate was transformed into stiffeners. Thus, the thickness of the reference plate $t=20 \mathrm{~mm}$ becomes $t_{p}=14 \mathrm{~mm}$. A total of 75 stiffened plates were analyzed, being: i) 25 with rectangular stiffeners oriented at $0^{\circ}$; ii) 25 with rectangular stiffeners oriented at $45^{\circ}$; iii) 25 with trapezoidal oriented at $0^{\circ}$. The equation that represents the volume fraction $\phi$ for the plates with rectangular stiffeners oriented at $0^{\circ}$ was defined by:

$$
\phi=\frac{V_{s}}{V_{r}}=\frac{n_{s x}\left(a h_{s} t_{s}\right)+n_{s y}\left[\left(b-n_{s x} t_{s}\right) h_{s} t_{s}\right]}{a b t}
$$

For the plates with rectangular stiffeners oriented at $45^{\circ}, \phi$ can be expressed by:

$$
\phi=\frac{V_{s}}{V_{r}}=\frac{\sum_{d=1}^{n}\left[\left(d_{1}+d_{2}+d_{3} \ldots d_{\mathrm{n}}\right) h_{s} t_{s}\right]-\left(n_{i n t} h_{s} t_{s}^{2}\right)}{a b t}
$$

and finally, for the plates with trapezoidal stiffeners oriented at $0^{\circ}, \phi$ is given as:

$$
\phi=\frac{V_{s}}{V_{r}}=\frac{\left\{n_{s x}\left[\frac{(a+c) h_{s} t_{s}}{2}\right]+n_{s y}\left[\frac{(b+d) h_{s} t_{s}}{2}\right]\right\}-V_{\text {int }}}{a b t}
$$

where $V_{s}$ is the volume of the stiffeners and $V_{r}$ is the volume of the reference plate. The length, width and thickness of the reference plate are, respectively, $a, b$ and $t ; h_{s}$ and $t_{s}$ are the height and thickness of stiffeners, respectively. As well $n_{s x}$ and $n_{s y}$ are the number of stiffeners in $x$ and $y$ directions. Exclusively for the Eq. (2), the parameters $d_{1}, d_{2}, d_{3}, \ldots d_{n}$ represents the stiffeners length, $n$ is the total number of stiffeners and $n_{\text {int }}$ is the number of intersections. Lastly regarding the Eq. (3), $c$ and $d$ are the smaller bases length of the trapezoidal stiffeners in $x$ and $y$ directions, fixed in $1000 \mathrm{~mm}$ and $500 \mathrm{~mm}$, respectively; and $V_{\text {int }}$ is the stiffeners intersection volume. All of these mentioned parameters can be seen in Fig. 6, which also presents a flowchart with all arrangements analyzed in this study.

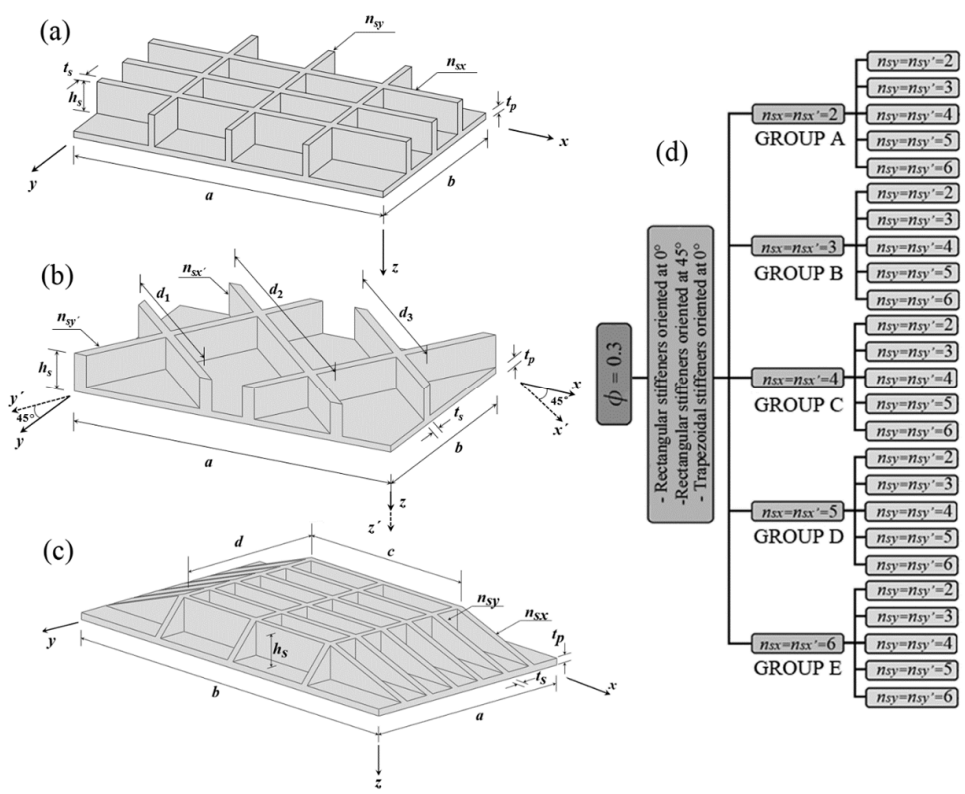

Fig. 6. (a) Plate $\mathrm{P}(3,3)$; b $\mathrm{P}^{\prime}(3,2)$; (c) $\mathrm{PT}(6,3)$; and (d) analyzed stiffened plate arrangements 
It is important to highlight that, $t_{s}$ was set as $19.21 \mathrm{~mm}$ (referent to the commercial size of 3/4") for all analyzed cases and the stiffener's high $h_{s}$ is variable as the number of stiffeners change, due to the CDM restriction on keeping the total volume of material constant. As well as, the performance indicator defined according to the CDM application is the maximum transverse (out-of-plane) deflection, and the goal is its minimization. Regarding the stiffeners directions, for the rectangular and trapezoidal configurations oriented at $0^{\circ}$, the traditional coordinate system with $x, y$ and $z$ was used (see Fig. 6 (a) and (c)), while for the configurations with stiffeners oriented at $45^{\circ}$, an auxiliary coordinate system $x^{\prime}, y^{\prime}, z^{\prime}$ was established (see Fig. 6(b)). Thus, the nomenclature $\mathrm{P}\left(n_{s x}, n_{s y}\right)$ and $\mathrm{P}_{\mathrm{T}}\left(n_{s x}, n_{s y}\right)$ for plates with rectangular and trapezoidal stiffeners, respectively, oriented at $0^{\circ}$, was adopted; in which $n_{s x}$ and $n_{s y}$ are the numbers of stiffeners in $x$ and $y$ directions. However, for the plates with rectangular stiffeners oriented at $45^{\circ}$, the format $\mathrm{P}^{\prime}\left(n_{s x^{\prime}}, n_{s y^{\prime}}\right)$ was employed and $n_{s x^{\prime}}$ and $n_{s y^{\prime}}$ are the number of stiffeners in $x^{\prime}$ and $y^{\prime}$ directions.

\section{Results and Discussion}

All analyzed plates were simulated using the triangular version of the finite element SHELL281 and were subjected to a uniform transverse loading of $10 \mathrm{kPa}$ with boundary conditions of simply supported edges. The material adopted was the structural steel A-36 with an elastic modulus of $200 \mathrm{GPa}$ and Poisson ratio of 0.3 . Prior, a mesh convergence test was performed in order to determine the suitable size of the finite elements that would be used in all numerical simulations. To do so, the plate with more complex geometry P' $(6,6)$ with $h_{s}=49.495 \mathrm{~mm}$ was adopted. A total of 6 different meshes densities were analyzed, in each one of them, the size of the finite elements was successively reduced. The result of the mesh convergence test can be observed in Table 1. According to Table 1, from the mesh $\mathrm{M}_{3}$ the values for the maximum deflection were stabilized, being the mesh $\mathrm{M}_{3}$ with finite element size of $25 \mathrm{~mm}$ adopted for the numerical simulations performed in the present study.

Table 1. Mesh convergence test

\begin{tabular}{llll}
\hline Mesh & Size of the Finite Elements & Number of Finite Elements & $U_{z \operatorname{Max}}(\mathbf{m m})$ \\
\hline $\mathrm{M}_{1}$ & 100.00 & 1210 & 0.198 \\
$\mathrm{M}_{2}$ & 50.00 & 2730 & 0.199 \\
$\mathrm{M}_{3}$ & 25.00 & 9860 & 0.200 \\
$\mathrm{M}_{4}$ & 16.67 & 21460 & 0.200 \\
$\mathrm{M}_{5}$ & 12.50 & 38000 & 0.200 \\
$\mathrm{M}_{6}$ & 10.00 & 59230 & 0.200 \\
\hline
\end{tabular}

The results of the all analyzed stiffened plates, concerning the maximum deflection are presented in Fig.7. The bar graph format allows that the variation of the deflections magnitude be easily observed for the three different situations of stiffeners configurations.

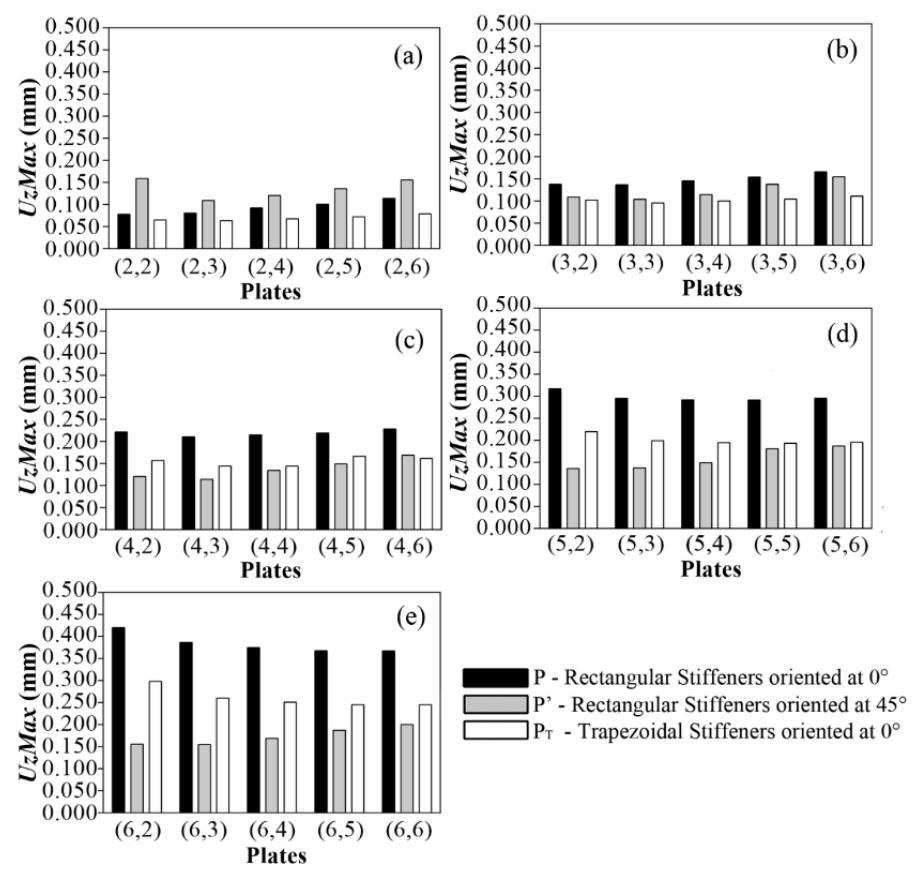

Fig. 7. Results for the maximum deflection of the stiffened plates: (a) Group A; (b) Group B; (c) Group C; (d) Group D; (e) Group E 
Taking into account that the maximum deflection of the non-stiffened reference plate is $U_{z M a x}=0.697 \mathrm{~mm}$, from Fig. 7 it is possible to infer that transforming a portion of the reference plate material into stiffeners improves the mechanical behavior regarding the maximum deflection. Comparing the best result among all geometries, which was reached by the plate with trapezoidal stiffeners at $0^{\circ} \mathrm{P}_{\mathrm{T}}(2,3)$ with the reference plate, there was a reduction of $90.9 \%$ for the $U_{z \text { Max }}$. Comparing the plate with trapezoidal stiffeners oriented at $0^{\circ} \mathrm{P}_{\mathrm{T}}(2,3)$, which presented the smallest deflection among all studied cases, with the rectangular plate with the same orientation $\mathrm{P}(2,3)$, a reduction in the deflection was $21.36 \%$. However, in the comparison between the plates $\mathrm{P}_{\mathrm{T}}(2,3)$ and $\mathrm{P}^{\prime}(2,3)$ with rectangular stiffeners at $45^{\circ}$, the plate with trapezoidal stiffeners at $0^{\circ} \mathrm{P}_{\mathrm{T}}(2,3)$ presented a maximum deflection $42.1 \%$ lower than the plate $\mathrm{P}^{\prime}(2,3)$. The deflections distribution of these plates can be observed at Fig. 8, where it is possible to visualize the minimization of the maximum deflection presented by the plate $\mathrm{P}_{\mathrm{T}}(2,3)$ with trapezoidal stiffeners (Fig. 8(c)).

(a)

(b)

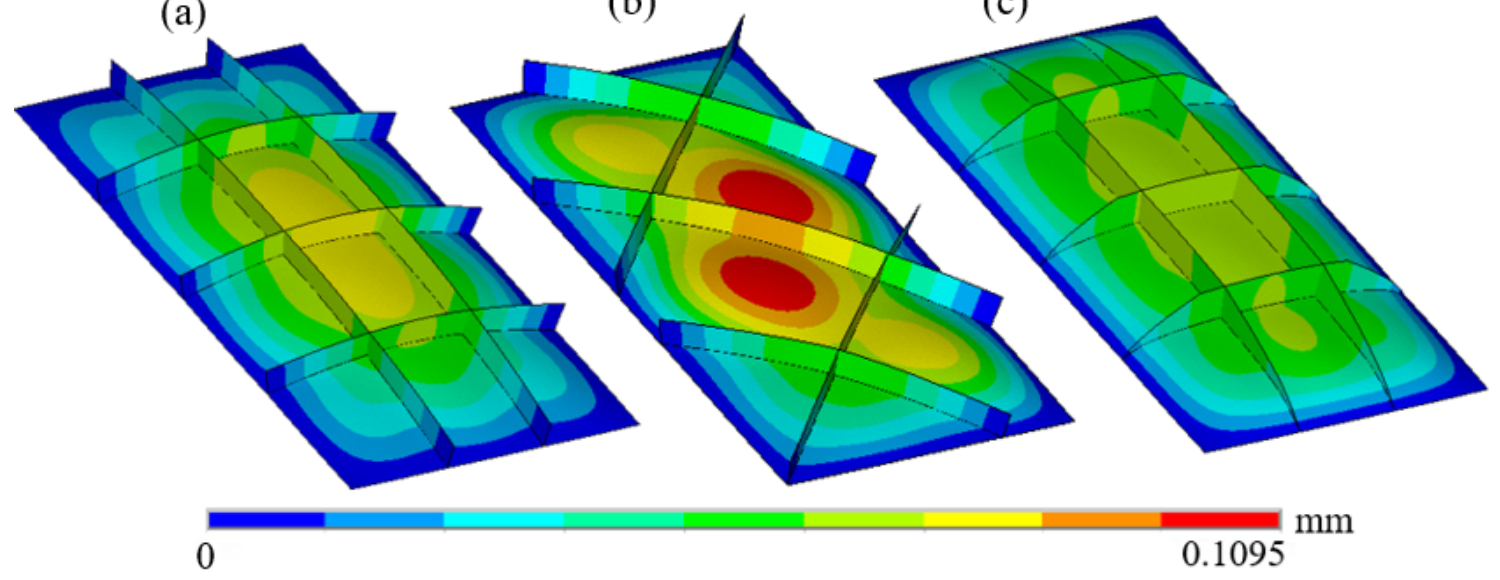

Fig. 8. Transverse displacements distribution for plates: (a) $\mathrm{P}(2,3)$; (b) $\mathrm{P}^{\prime}(2,3)$; and (c) $\mathrm{P}_{\mathrm{T}}(2,3)$.

One can note from Fig. 8, that the plate $\mathrm{P}_{\mathrm{T}}(2,3)$ (Fig. 8(c)) has the ability to promote a more uniform distribution for the out-of-plane displacements, which can be explained by the Constructal Principle of Optimal Distribution of Imperfections. So, considering in this study the deflections as the imperfections of the physical system, the best geometric configuration is the one which distributes these imperfections in a more homogeneous way. This trend was already observed in previous works of structural engineering, as in Da Silva et al. (2019), Lima et al. (2020) and Silveira et al. (2021). Still analyzing the results of Fig. 7 and concerning the percentage differences related to maximum deflection among all studied configurations of trapezoidal and rectangular stiffeners at $0^{\circ}$, the major difference occurred between the plates $\mathrm{P}_{\mathrm{T}}(5,6)$ and $\mathrm{P}(5,6)$, where the plate with trapezoidal stiffeners showed a reduction of $33.86 \%$ in the maximum deflection. Moreover, comparing plates with trapezoidal stiffeners at $0^{\circ}$ and rectangular stiffeners at $45^{\circ}$ regarding the percentage differences of the maximum deflection, the larger difference was found between the plates $\mathrm{P}_{\mathrm{T}}(6,2)$ and $\mathrm{P}^{\prime}(6,2)$, where the plate with rectangular stiffeners at $45^{\circ}$ presented a maximum deflection $47.70 \%$ lower than the plate with trapezoidal stiffeners at $0^{\circ}$.

In its turn, regarding to maximum deflection percentage differences, the main difference between plates with rectangular stiffeners oriented at $0^{\circ}$ and rectangular stiffeners at $45^{\circ}$ was for the plates $\mathrm{P}(6,2)$ and $\mathrm{P}^{\prime}(6,2)$, being the maximum deflection presented by $\mathrm{P}^{\prime}(6,2) 62.95 \%$ smaller than the occurred in $\mathrm{P}(6,2)$.

It was also noted in Fig. 7 that the maximum deflections tend to be larger as the number of stiffeners increases, for instance the Groups D and E. This can be explained due to the main restriction of the problem (keeping the total volume of material constant): the greater the number of stiffeners, the smaller its height $h_{s}$, decreasing the moment of inertia of the stiffeners cross section and the rigidity of the plates, consequently increasing the deflections. Generally, it was observed from Fig. 7 that all results for the plates with trapezoidal stiffeners oriented at $0^{\circ}$ presented smaller maximum deflections when compared with the results presented by the plates with rectangular stiffeners oriented at $0^{\circ}$. However, when comparing the plates with trapezoidal stiffeners at $0^{\circ}$ with the plates with rectangular stiffeners at $45^{\circ}$, the results were better for the plates with trapezoidal stiffeners at $0^{\circ}$ only for the geometries within the Groups A and B. Moreover, excluding Group A, all the plates with rectangular stiffeners at $45^{\circ}$ performed better in comparison with the plates with rectangular stiffeners at $0^{\circ}$ concerning the maximum deflection.

\section{Conclusion}

Keeping constant the material volume, it can be concluded that transforming a portion of the non-stiffened plate material into stiffeners substantially improves the mechanical behavior by the reduction of the maximum deflection. Among the proposed stiffened plates the best geometric configuration, i.e., the geometry that minimizes the maximum deflection is the plate $\mathrm{P}_{\mathrm{T}}(2,3)$, achieving a reduction higher than $90 \%$ in comparison with the reference plate. In addition, the plates with trapezoidal stiffeners at $0^{\circ}$ proved to be more efficient for the reduction of the maximum deflection than the plates with 
rectangular stiffeners also oriented at $0^{\circ}$. However, for the majority of the analyzed geometric configurations, the plates with rectangular stiffeners oriented at $45^{\circ}$ presented the best mechanical behavior with respect to the reduction in the maximum deflection when compared to the plates with trapezoidal and rectangular stiffeners at $0^{\circ}$. Thus, the application of the CDM associated with numerical models developed by means of the FEM and the ES technique can lead to great results regarding the mechanical behavior of stiffened plates. As suggestion for future researches, it is possible to investigate other geometric configurations of the stiffened plates (e.g. plates with trapezoidal stiffeners oriented at $45^{\circ}$ ) as well as other values of stiffeners volume fraction $\phi$. In addition, other performance parameters can be adopted, such as the minimization of the maximum stress; and even a multi-objective investigation considering concomitantly the minimization of the maximum deflection and the maximum stress.

\section{Acknowledgement}

This study was financed in part by the Coordenação de Aperfeiçoamento de Pessoal de Nivel Superior - Brasil (CAPES) Finance Code 001. Particularly, the authors L. A. O. Rocha, E. D. dos Santos, and L. A. Isoldi also thank to Conselho Nacional de Desenvolvimento Científico e Tecnológico - Brasil (CNPq) for their research grants (Processes: 307791/2019-0, 306024/2017-9, and 306012/2017-0, respectively).

\section{References}

Ansys Academic Research Mechanical, Release 19, Help System, Element Reference, ANSYS, Inc.

Bedair, O. K. (2006). Analysis and Limit State Design of stiffened plates and shells: A world view. Applied Mechanics Reviews, 62(2), 01-16. DOI: 10.1115/1.3077137

Bejan, A. \& Zane, J. P.(2012). Design in Nature: How the Constructal Law governs evolution in biology, physics, technology, and social organizations. New York: Doubleday.

Carrijo, E.C, Paiva, J.B. \& Giogo, J.S. (1999). A numerical and experimental study of stiffened plates in bending. Transactions on Modelling and Simulation, 21, 12-18, DOI: 10.2495/CMEM990021

Cunha, M. L., Troina, G. S., Rocha, L. A. O., dos Santos, E. D., Isoldi, L. A. (2018). Computational modeling and Constructal Design method applied to the geometric optimization of stiffened steel plates subjected to uniform transverse load. Research on Engineering Structures and Materials, 4(3), 139-149. DOI: 10.17515/resm2017.18st1118

Da Silva, C. C. C., Helbig, D., Cunha, M. L., Dos Santos, E. D., Rocha, L. A. O.; Real, M. V., Isoldi, L. A. (2019). Numerical buckling analysis of thin steel plates with centered hexagonal perforation through constructal design method. Journal of the Brazilian Society of Mechanical Sciences and Engineering, 41(8), 309-1-309-18. DOI: 10.1007/s40430-019-1815-7

De Queiroz, J., Cunha, M.L., Pavlovic, A., Rocha, L. A. O, Dos Santos, E. D., Troina, G.S., Isoldi, L.A. (2019). Geometric Evaluation of Stiffened Steel Plates Subjected to Transverse Loading for Naval and Offshore Applications. Journal of Marine Science and Engineering, 7(1) ,7-18. DOI: 10.3390/jmse7010007

Dos Santos, E. D., Isoldi, L. A., Gomes, M. N., Rocha, L. A. O. (2017). The Constructal Design Applied to Renewable Energy Systems. In Rincón-Mejía. E \& De las Heras. A (Ed.), Sustainable Energy Technologies 1ed. 63-87, Boca Raton: CRC Press - Taylor \& Francis Group. DOI: 10.1201/9781315269979

Helbig, D., Cunha, M. L., Da Silva, C. C. C., Dos Santos, E. D., Iturrioz, I. Real, M. V., Isoldi, L. A.; Rocha, L. A. O. (2018). Numerical study of the elasto-plastic buckling in perforated thin steel plates using the constructal design method. Research on Engineering Structures and Materials, 4(3), 169-187. DOI: 10.17515/resm2017.37ds1123

Isoldi, L. A., Real, M. V., Vaz, J., Correia, A. L. G., Dos Santos, E. D., Rocha, L. A. O. (2013). Numerical analysis and geometric optimization of perforated thin plates subjected to tension or buckling. Marine Systems \& Ocean Technology, $8(2), 99-107$.

Isoldi, L. A., Real, M. V., Correia, A. L. G., Vaz, J., Dos Santos, E. D., Rocha, L. A. O. (2013). Flow of Stresses: Constructal Design of Perforated Plates Subjected to Tension or Buckling. In Rocha, L. A. O., Lorente, S., Bejan, A. (Ed.), Constructal Law and the Unifying Principle of Design - Understanding Complex Systems 1ed. (pp.195-127). New York: Springer.

Lorenzini, G., Helbig, D., Da Silva, C. C. C., Real, M. V., Dos Santos, E. D., Isoldi, L. A., Rocha, L. A. O. (2016). Numerical evaluation of the effect of type and shape of perforations on the buckling of thin steel plates by means of the Constructal Design method. International Journal of Heat and Technology, 34(1), s9-s20. DOI: 10.18280/ijht.34S102

Lima, J. P. S., Rocha, L. A. O., Dos Santos, E. D., Real, M. V., Isoldi, L. A. (2018). Constructal design and numerical modeling applied to stiffened steel plates submitted to elasto-plastic buckling. Proceedings of the Romanian Academy Series AMathematics Physics Technical Sciences Information Science, 19, 195-200.

Nogueira, C., Pinto, V., Rocha, L., Santos, E., \& Isoldi, L. (2021). Numerical simulation and constructal design applied to plates with different heights of traverse and longitudinal stiffeners. Engineering Solid Mechanics, 9(2), 221-238.

O’Leary, J. R. \& Harari, I. (1985). Finite element analysis of stiffened plates. Computers \& Structures, $21(5), 973-985$.

Pama, R.P \& Cusens, A.R. (1969). Edge beam stiffening of multibeam bridges. Journal of the Structural Division, 93, 141161.

Powell, G.H. \& Ogden, D. W. (1969). Analysis of orthotropic steel plate bridge decks. Journal of the Structural Division, 95, 909-921. 
Rappaz, M., Bellet M., \& Deville, M. (2010). Numerical Modeling in Materials Science and Engineering. Heidelberg: Springer. DOI: 10.1007/978-3-642-11821-0

Sapountzakis, E. J. \& Katsikadelis, J. T. (2000). Analysis of Plates Reinforced with Beams. Computational Mechanics, 26(1), 66-74, 2000. DOI: $10.1007 / \mathrm{s} 004660000156$

Singh, D. K., Duggal S. K., \& Pal, P. (2015). Analysis of Stiffened Plates using FEM - A Parametric Study. International Research Journal of Engineering and Technology, 2(4), 1650-1656.

De Silveira, T., Pinto, V.T., Neufeld, P.D.S., Pavlovic, A., Rocha, L. A. O., Dos Santos, E. D., \& Isoldi, L. A. (2021). Applicability Evidence of Constructal Design in Structural Engineering: Case Study of Biaxial Elasto-Plastic Buckling of Square Steel Plates with Elliptical Cutout. Journal of Applied and Computational Mechanics, 7(2), 922-934. DOI: 10.22055/JACM.2021.35385.2647

Szilard R. (2004). Theories and applications of plate analysis: Classical numerical and engineering methods. $1^{a}$ ed. Hoboken: Wiley. DOI: 10.1002/97804701728722

Reis A.H. (2006). Constructal theory: from engineering to physics, and how flow systems develop shape and structure. Applied Mechanics Reviews, 59(5),269-281. DOI: 10.1115/1.2204075

Tanaka, M., Matsumoto, T., \& Oida, S. A. (2000). Boundary Element Method Applied to the Elastostatic Bending Problem of Beam-stiffened Plates. Engineering Analysis with Boundary Elements, 24(10),751-758.

Thompson, M. K. \& Thompson, J. M. (2017). ANSYS Mechanical APDL for Finite Element Analysis. Kidlington: Elsevier.

Troina, G.S., de Queiroz, J.P.T.P., Cunha, M.L., Rocha, L.A.O., dos Santos E.D., \& Isoldi, L.A. (2018). Verificação de modelos computacionais para placas com enrijecedores submetidas a carregamento transversal uniforme. CEREUS, 10(2), 285-298.

Troina, G.S., Cunha, M.L., Pinto, V.T., Rocha, L.A.O., Dos Santos, E.D., Fragassa, C. \& Isoldi, L.A. (2020). Computational Modeling and Design Constructal Theory Applied to the Geometric Optimization of Thin Steel Plates with Stiffeners Subjected to Uniform Transverse Load. Metals, 10, 1-29. DOI: 10.3390/met10020220

Ugural, A. C. (2010). Stresses in beams, plates, and shells. 3.ed. Boca Raton: CRC Press.

Ventsel, E. \& Krauthammer, T. (2001). Thin Plates and Shells: Theory, Analysis and Applications. $1^{a}$ ed. New York: Marcel Dekker, DOI: 10.1201/9780203908723 
(C) 2022 by the authors; licensee Growing Science, Canada. This is an open access article distributed under the terms and conditions of the Creative Commons Attribution (CC-BY) license (http://creativecommons.org/licenses/by/4.0/). 